\section{A NEW SYNTHETIC ANTIBIOTIC ANALOG OF GRAMICIDIN S, [2,2'-L-SERINE]-GRAMICIDIN S}

Sir :

In studies of relationship between structure and antibacterial activity of gramicidin S, various analogs have been synthesized. From these studies, it has been recognized that the basic amino groups of ornithine residues in gramicidin $\mathrm{S}$ are necessary for the activity. For example, acylation of the amino groups in ornithine residues caused drastic decrease in the activity ${ }^{1)}$. On the other hand, changing the length of the side chain in the ornithine residues ${ }^{2,3)}$ and conversion of the amino groups into strongly basic guanidino groups does not alter the activity ${ }^{4}$. Recently, [His $\left.{ }^{2}{ }^{\prime}\right]-G S$, in which the ornithine residues are replaced by histidine residues, was synthesized and shown to be $1 / 8$ or $1 / 16$ times as active as gramicidin $\mathbf{S}^{5}$.

In order to investigate the biological role of $\delta$-amino groups in ornithine residues, we synthesized the gramicidin analog, $\left[\mathrm{Ser}^{2,{ }^{\prime}}\right]-\mathrm{GS}$, in which these are replaced by serine residues (Fig. 1).

The compound was synthesized by conventional methods. Boc-Val-Ser hydrazide and LeuD-Phe-Pro-OBzl, synthesized by DCC coupling using 1-hydroxybenztriazole, were joined to form Boc-Val-Ser-Leu-D-Phe-Pro-OBzl, which in part was converted to the Boc-pentapeptide

Fig. 1
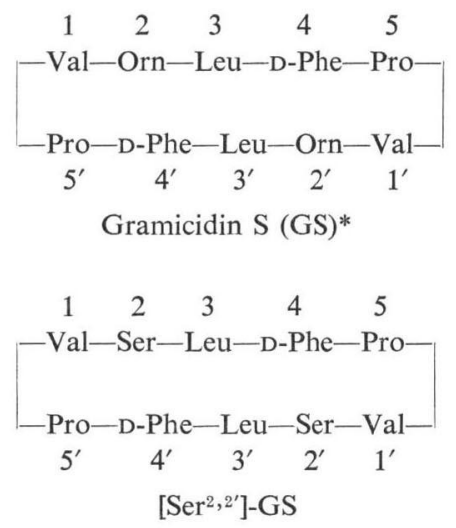

* Abbreviations with no prefix show L-amino acid residue.

** The following are from J. Biol. Chem. 247: hydrazide*,**). Coupling of Boc-pentapeptide hydrazide and peptapeptide ester derived from the protected ester afforded Boc-(Val-Ser-LeuD-Phe-Pro) ${ }_{2}$-OBzl. This ester was converted into the corresponding hydrazide, and then cyclized by azide method using pyridine. The cyclodecapeptide, [Ser $\left.{ }^{2}{ }^{2}\right]$-GS, was obtained in $60 \%$ yield. The homogeneity of $\left[\mathrm{Ser}^{2,2}\right]$-GS was confirmed by means of thin-layer chromatography, amino acid analysis, and elemental analysis.

The antibacterial activity toward several microorganisms was examined, and the results are shown in Table 1. This analog has antibacterial activity against some Gram-positive microorganisms, in spite of the absence of the ornithine amino groups. However, its activity is less by about one order than that of natural gramicidin $\mathbf{S}$.

The ORD and CD spectra of this analog were measured in ethanol. Its ORD spectrum shape resembled that of gramicidin $\mathrm{S}$, and a trough was observed at $234 \mathrm{~nm}$ like that of gramicidin S. In the $\mathrm{CD}$ spectrum was also observed a curve similar to that of gramicidin $\mathrm{S}$, and the two troughs at $209 \mathrm{~nm}$ and $217 \mathrm{~nm}$ were slightly shallower than those of gramicidin S. The results of these spectra indicate that the conformation of the analog is similar to that of gramicidin $\mathrm{S}$.

For the mode of action of gramicidin $\mathrm{S}$, it has been reported by S. N. Semenov et al. ${ }^{6)}$ that the

Table 1. Antibacterial activity of GS and its analog.

\begin{tabular}{l|c|c}
\hline \multirow{2}{*}{ Strain } & \multicolumn{2}{|c}{$\begin{array}{c}\text { Minimum inhibitory } \\
\text { concentration, } \\
\mu \mathrm{g} / \mathrm{ml}\end{array}$} \\
\cline { 2 - 3 } & $\mathrm{GS}$ & $\begin{array}{c}\left.\text { [Ser }{ }^{2}, 2^{\prime}\right]- \\
\mathrm{GS}\end{array}$ \\
\hline $\begin{array}{c}\text { Staph. aureus ATCC } \\
\text { 6538P }\end{array}$ & 6.3 & $>100$ \\
Strept. pyogenes N.Y.5 & 1.6 & 25 \\
Micrococcus flavus & 1.6 & 12.5 \\
ATCC 10240 & 0.8 & 6.3 \\
Corynebact. diphtheriae & & \\
P.W.8 & 1.6 & $>100$ \\
Bac. subtilis ATCC 6633 & $>100$ & $>100$ \\
E. coli NIHJ-JC2 & & \\
\hline
\end{tabular}

977 983, 1972: Boc-, t-butoxycarbonyl; DCC, dicyclohexylcarbodiimide. 
most significant role for the gramicidin $\mathrm{S}$ membrane activity is played by the "pleated sheet" conformation, while free amino groups of ornithine residues are involved only in the formation of amino group-lipid complexes. In the present study, it is noteworthy that the activity of this synthetic analog might simulate not gramicidin $\mathbf{S}$ proper, but its active complex directly.

\section{Acknowledgment}

We are grateful to members of the Research Laboratories of Toyo Jozo Co. for their elemental analyses and microbiological assays. We also thank Mr. Y. Мотокі, Rikkyo (St. Paul's) University, Department of Chemistry, for the amino acid analyses.

\section{MAKOTO TAMAKI \\ Michiaki TAKimoto \\ ShŌSUKe SōfukU* \\ IChiro Muramatsu*}

Department of Chemistry, Faculty of Science,

Toho University,

Miyama, Funabashi,

Chiba, Japan

*Department of Chemistry,

College of Science,

Rikkyo (St. Paul's) University,

Nishi-ikebukuro,

Tokyo, Japan

(Received August 27, 1979)

\section{References}

1) Kaprel'yants, A. S.; V. V. Nikiforov, A. I. Miroshnikov, L. G. Snezhrova, V. A. Eremin \& D. N. Ostrovski: Bacterial membranes and mechanism of action of gramicidin S. Biochemistry (translated from Russian) 42: 252 257, 1977

2) Schwyzer, R. \& P. Sieber: A synthetic analog of gramicidin S, Cyclo (Val-Lys-Leu-D-PhePro $)_{2}$. Helv. Chim. Acta 41: 1582 1587, 1958

3) WaKi, M.; O. Abe, R. OKawa, T. Kato, S. Makisumi \& N. Izumiya: Studies of peptide antibiotics. XII. Syntheses of [2,2'- $\alpha, \gamma$-diaminobutyric acid]- and [2,2'-lysine]-gramicidin $\mathrm{S}$. Bull. Chem. Soc. Jpn. 40: 2904 2909, 1967

4) Silaev, A. B. \& V. M. Stepanov: Significance of free amino group of gramicidin $\mathrm{S}$ for its biological activity. Dokl. Akad. Nauk SSSR. 112: $297 \sim 299,1957$

5) Nonaka, K.; K. Sato, S. Terada, T. Kato \& N. IzumiYa: Studies of peptide antibiotics. XXXIX. Syntheses of gramicidin S analogs containing L-histidine in place of L-ornithine. Bull. Chem. Soc. Jpn. 51: 2127 2130, 1978

6) Semenov, S. N.; E. I. Mel'nik, L. G. Snezhkova, A. I. Miroshnikov \& V. T. Ivanov: Study of the interaction of gramicidin $\mathrm{S}$ with model lipid systems. Bioorg. Khim. 3: 1055 1063, 1977

Ivanov, V. T.: Solution structures of peptides. in Peptides. Goodman, M. \& J. Meienhofer, $E d s$, John Wiley and Sons, Inc., New York, pp. $307 \sim 321,1977$ 